\title{
Heart Diseases in Pregnancy and Preoperative Evaluation
}

\author{
Muhammet Dural*, [MD] \\ Hikmet Yorgun ${ }^{1}$, [MD] \\ ${ }^{1}$ Hacettepe University Faculty of Medicine, Department \\ of Cardiology, Ankara, Turkey
}

*Corresponding Author: Muhammet Dural, M.D.

Eskişehir Osmangazi University Faculty of Medicine

Department of Cardiology 26040, Odunpazarı,

Eskişehir/Turkey

Tel: 0902222392979

Fax: 0902222393772

Email: muhammet_dural@hotmail.com

DOI: https://doi.org/10.32552/2018.ActaMedica.332

\author{
nep ABSTRACT Cen
}

Increased prevalence of cardiovascular risk factors (diabetes mellitus, hypertension, obesity) and age at first gestation are the important factors that increase cardiovascular diseases incidence in pregnancy. Assessment of maternal and fetal risk is very important. In World Health Organization class 1, the risk is very low and it is recommended that the cardiologic evaluation be performed once or twice in pregnancy. World Health Organization class 2 patients have low to moderate risk and cardiology consultation is recommended at every trimester. World Health Organization class 3 patients have a high risk, so cardiology consultation is recommended monthly or bi-monthly. Pregnancy is not recommended for World Health Organization class 4 patients. In cases where surgery is necessary the general approach is the same as those who are not pregnant. However, a multidisciplinary approach is needed in pregnant patients. Surgery should be performed independently of the trimester in emergent cases. If an elective intervention is needed and there is no effect on fetus, the surgical procedure should be delayed after birth. If surgery is needed and semi-elective, the optimal time period is indicated as second trimester. The type of anesthesia to be applied is determined according to the type and timing of surgery, maternal physiological changes and teratogenic effects.

Keywords: Heart disease, pregnancy, preoperative evaluation.

Received: 08 August 2018, Accepted: 25 November 2018, Published online: 25 December 2018

\section{INTRODUCTION}

Cardiovascular diseases (CVD) are seen in 0,2-4\% of pregnancies in western countries [1]. However, an appropriate treatment approach can not be applied to a significant part of these patients. The treatment that is appropriate for the mother can damage the baby, on the other hand treatment approaches for protecting the baby can be harmful to the mother. Increased prevalence of cardiovascular risk factors (diabetes mellitus, hypertension, obesity) and age at first gestation are the important factors that increase CVD incidence in pregnancy. In addition, improvements in the treatment of congenital heart diseases (CHD) have increased the number of women with heart disease reaching the age of fertility [2]. Maternal heart diseases in Western countries have become the main cause of maternal deaths in pregnancy [3].

Hypertensive diseases are the most common cardiovascular events in pregnancy and occur in 6-8\% of all pregnancies [4]. In Western countries, CHDs are the most common CVD in pregnancy (75$82 \%)$ and most of them are shunt lesions (20-65\%) [5]. In non-Western countries, rheumatic valve diseases account for $56-89 \%$ of pregnant CVDs [6].

\section{Heart Disease in Pregnancy 1.1. Evaluation of Maternal and Fetal Risk}

CARPREG risk score is the most commonly known and most commonly used risk score [6]. (Table 1). In addition, the World Health Organization (WHO) risk classification [7] includes all known maternal cardiovascular risk factors and comorbidities (Table 2 and 3). In WHO class 1, the risk is very low and it is recommended that the cardiologic evaluation be performed once or twice in pregnancy [3]. WHO 
Table 1. Predictors of maternal cardiovascular events according to CARPREG [6] study

\begin{tabular}{|l|}
\hline Cardiac event history (heart failure, transient ischemic attack, stroke or arrhythmia) \\
\hline Baseline NYHA functional classification \\
\hline Left heart obstruction (Mitral valve area $<2 \mathrm{~cm}^{2}$, aortic valve area $<1.5 \mathrm{~cm}^{2}$, peak left ventricular outflow gradient $>$ \\
$30 \mathrm{mmHg}$ ) \\
\hline Decreased left ventricular systolic function (LVEF $<40 \%$ ) \\
\hline
\end{tabular}

NYHA: New York Heart Association, LVEF: Left ventricular ejection fraction

class 2 patients have low to moderate risk and cardiology consultation is recommended at every trimester [3]. WHO class 3 patients have a high risk, so cardiology consultation is recommended monthly or bi-monthly [3]. Pregnancy is not recommended for WHO class 4 patients, but if pregnant and does not accept termination cardiology consultation is recommended every month or bi-monthly [3].

Table 2. Modified WHO classification of maternal cardiovascular risk: general principles [3]

\begin{tabular}{|l|l|}
\hline Risk classification & Risk of pregnancy according to medical condition \\
\hline 1 & $\begin{array}{l}\text { There is no increase in maternal mortality and there is no in- } \\
\text { crease or slight increase in morbidity. }\end{array}$ \\
\hline 2 & $\begin{array}{l}\text { There is slight increase in maternal mortality or moderate in- } \\
\text { crease in morbidity. }\end{array}$ \\
\hline 3 & $\begin{array}{l}\text { There is a significant increase in maternal mortality or a risk } \\
\text { of severe morbidity. If continued pregnancy is decided, spe- } \\
\text { cial cardiac and obstetric follow-up is needed during preg- } \\
\text { nancy, during delivery and postpartum period. }\end{array}$ \\
\hline 4 & $\begin{array}{l}\text { There is a very high risk of maternal mortality or severe mor- } \\
\text { bidity. Pregnancy is contraindicated. Termination should be } \\
\text { recommended. If continued pregnancy is decided, it should } \\
\text { be approached as class 3. }\end{array}$ \\
\hline
\end{tabular}

Tablo 3. Modified WHO classification of maternal cardiovascular risk: approach and practice [3]

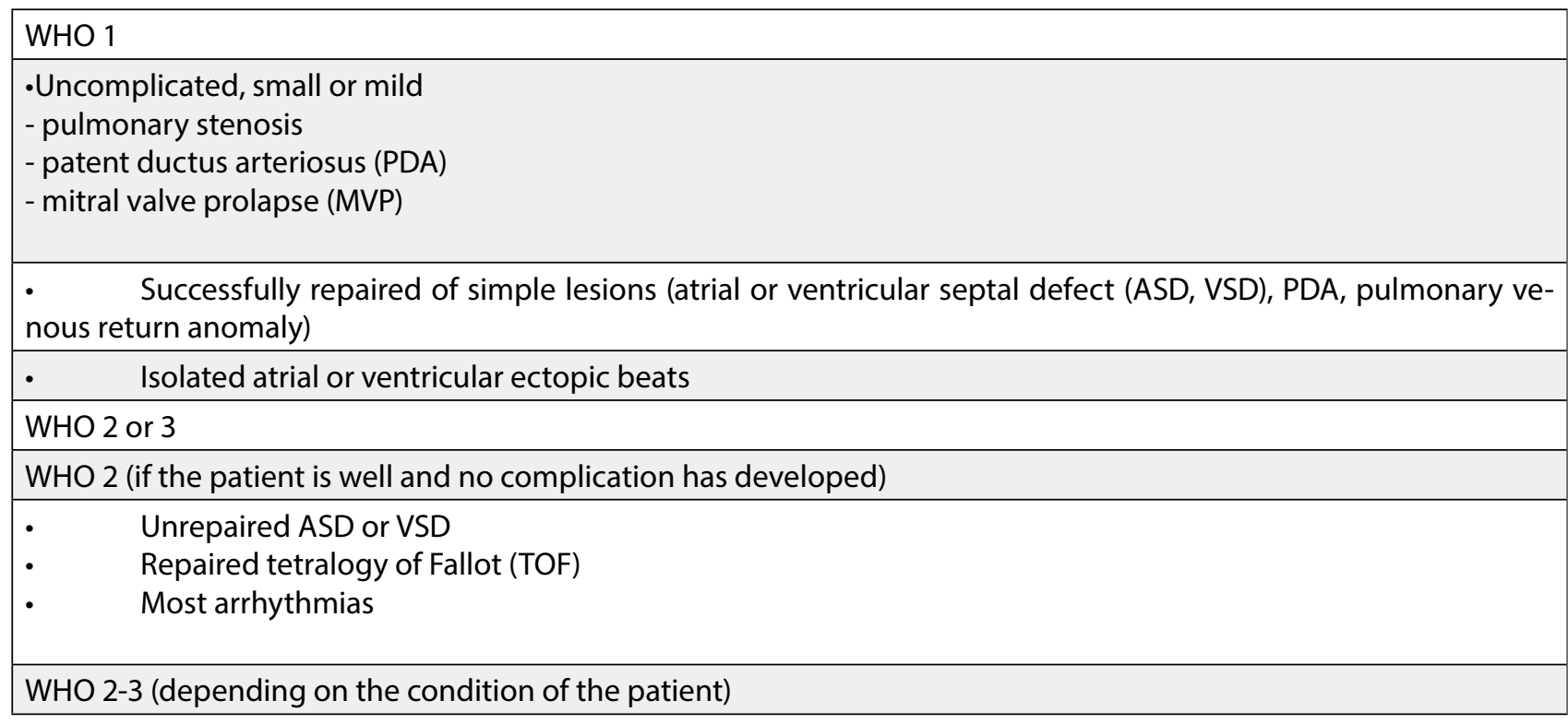




\begin{tabular}{|c|c|}
\hline $\begin{array}{l}\cdot \\
\dot{\bullet} \\
\dot{ } \\
\dot{ } \\
\text { - }\end{array}$ & $\begin{array}{l}\text { Mild left ventricular dysfunction } \\
\text { Hypertrophic cardiomyopathy } \\
\text { Valvular heart disease which is not in WHO } 1 \text { or } 4 \\
\text { Marfan syndrome without aortic dilatation } \\
\text { Bicuspid aortic valve and the ascendan aorta is }<45 \mathrm{~mm} \\
\text { Corrected aortic coarctation }\end{array}$ \\
\hline \multicolumn{2}{|c|}{ WHO 3} \\
\hline $\begin{array}{l}\dot{ } \\
\dot{\bullet} \\
\dot{ } \\
\dot{ } \\
\text {. }\end{array}$ & $\begin{array}{l}\text { Mechanical heart valve } \\
\text { Systemic right ventricle } \\
\text { Fontan circulation } \\
\text { Cyanotic heart disease (unrepaired) } \\
\text { Other complex congenital heart diseases } \\
\text { Marfan syndrome and the aorta is } 40-45 \mathrm{~mm} \\
\text { Bicuspid aortic valve and the aorta is } 45-50 \mathrm{~mm}\end{array}$ \\
\hline \multicolumn{2}{|c|}{ WHO 4 (pregnancy is contraindicated) } \\
\hline $\begin{array}{l}\cdot \\
\cdot \\
\cdot \\
\cdot \\
\cdot \\
\cdot \\
\cdot\end{array}$ & $\begin{array}{l}\text { Pulmonary arterial hypertension (PAH) due to any cause } \\
\text { Severe systemic ventricular dysfunction (LVEF <30\%, NYHA 3-4) } \\
\text { Peripartum cardiomyopathy, which is impaired in any residual left ventricular function } \\
\text { Severe mitral stenosis, severe symptomatic aortic stenosis } \\
\text { Marfan syndrome and the aorta is }>45 \mathrm{~mm} \\
\text { Bicuspid aortic valve with }>50 \mathrm{~mm} \text { aorta } \\
\text { Severe aortic coarctation }\end{array}$ \\
\hline
\end{tabular}

Neonatal complications occur in $20-28 \%$ of those with heart disease and neonatal mortality is reported to be around 1-4\% [6-8] (Table 4).

Tablo 4. Maternal predictors of neonatal events in women with heart disease [3].

\begin{tabular}{|l|}
\hline 1. Basal NYHA $>2$ or cyanosis \\
\hline 2. Maternal left heart obstruction \\
\hline 3. Tobacco use during pregnancy \\
\hline 4. Multiple pregnancy \\
\hline 5. Use of oral anticoagulation in pregnancy \\
\hline 6. Mechanical valve prosthesis \\
\hline
\end{tabular}

\section{i1.2. Maternal High-Risk Conditions (WHO 3-4) Pulmonary Hypertension}

Maternal deaths are due to pulmonary hypertensive crisis, pulmonary thrombosis or refractory right heart failure, usually in the last trimester and the first month after birth. This can occur even in patients who have no symptoms or mild symptoms before and during pregnancy. In these patients, termination of pregnancy should be recommended [3]. If the patient accepts all risks and decides to continue the pregnancy, it is recommended that these patients be followed up at centers where all treatment options for PAH are available [9].

Attempts should be made to prevent systemic hypotension, acidosis and hypoxia, which may trigger refractory heart failure. Patients who use PAHspecific agents before pregnancy are advised to continue with these drugs during pregnancy, but it should be explained that certain drugs, such as bosentan, may have teratogenic effects [3].

The type of delivery should be determined according to the condition of the patient. Planned cesarean section and vaginal delivery should be preferred to emergency cesarean birth [3].

\subsection{Maternal Low and Moderate Risk Conditions (WHO 1-2 and 3)}

If exercise tolerance is good, ventricular function is 
normal, functional status is good, and there is no mechanical heart valve implantation, pregnancy is generally well tolerated in patients who have previously undergone successful surgical repair. Patients should be seen at the end of first trimester and the follow-up plan should be determined according to the patient. Vaginal birth can be planned in most cases [10-11].

\subsection{Spesific Congenital Heart Defects Atrial Septal Defect}

Pregnancy is well tolerated in most patients. The only contraindication is that PAH or Eisenmenger syndrome is developed. Hemodynamically significant ASD is recommended to be closed before pregnancy. Preeclampsia and low gestational age are more common in unrepaired ASD patients [3]. There is no additional risk for those with ASD who have been repaired [3].

\section{Ventricular Septal Defect}

The risk of complications is reported to be low in small perimembranous VSDs without left heart dilatation [12]. It is recommended to measure cardiac dimensions and measure pulmonary pressures before preg- nancy assessment in the presence of residual defects [3].

Tetralogy of Fallot

Surgical repair is required before the pregnancy in untreated patients. Those with repaired TOF can tolerate pregnancy. The most common complications are arrhythmia and heart failure [13]. Pre-pregnancy pulmonary valve replacement (homograft) is recommended for symptomatic women with significant right ventricular dilatation associated with severe pulmonary regurgitation [14].

\subsection{Chest Pain in Pregnancy Aortic Diseases}

Aortic dissection is an important cause of maternal mortality. The risk is highest in the last trimester and early postpartum period. For this reason, pregnancies with chest pain should definitely be evaluated in terms of aortic dissection.

\section{Coronary Artery Disease (CAD)}

Spontaneous coronary artery dissections are more common during the last period of pregnancy and postpartum period and the incidence is higher than normal population [15]. Women with known coronary artery disease should be evaluated before pregnancy and those with inducible ischaemia should be treated before pregnancy.

In patients with ST elevation myocardial infarction (STEMI), the management is same as for those who are not pregnant [3]. Coronary anjiogarphy (CAG) and if necessary percutaneous coronary intervention $(\mathrm{PCl})$ are recommended in the mid-high risk group of patients with non-ST elevation myocardial infarction (NSTEMI) [3]. ACE inhibitors and statins should not be used in pregnancy because they have fetal toxicity.

\subsection{Valvular Heart Disease in Pregnancy}

Stenotic diseases that may inhibit cardiac output increase can not be well tolerated during gestation and delivery. Regurgitant lesions are better tolerated.

In women of childbearing age, the cause of aortic stenosis (AS) is usually the bicuspid aortic valve. It may be associated with aortopathy. Pregnancy is not recommended in patients with symptomatic severe aortic stenosis, decreased performance in exercise testing and reduced left ventricular function, and valvular replacement is recommended prior to pregnancy [3]. Asymptomatic patients are advised to perform an exercise test in pre-pregnancy period to assess asymptomatic situation, exercise tolerance, blood pressure response, arrhythmia development, and / or intervention requirement [3]. In asymptomatic mild-moderate AS pregnancy is well tolerated. In addition, patients who are asymptomatic in the exercise test and who have severe AS with normal blood pressure response may well tolerate pregnancy [14]. Cesarean delivery is recommended in symptomatic patients, haemodynamic decompensation or patients with ascending aorta $>45$ $\mathrm{mm}$ [3].

Patients with moderate or severe MS are not recommended for pregnancy and even if they are asymptomatic, pre-pregnancy intervention is recommended (preferred percutaneous intervention) [3]. If symptom or pulmonary hypertension develops (systolic pulmonary artery pressure $>50 \mathrm{mmHg}$ on echocardiography) activity restriction and beta blocker initiation is recommended [3]. Diuretics may be added if the symptoms persist. In patients with severe MS, planning for elective percutaneous valvotomy after the 20th week in the second trimester 
is recommended if the patient is NYHA class III / IV and / or systolic pulmonary artery pressure is $>$ $50 \mathrm{mmHg}$ despite optimal medical treatment [3]. Cesarean delivery is recommended in patients with NYHA class III / IV or pulmonary hypertension despite medical treatment [3].

In regurgitant lesions, maternal cardiovascular risk depends on the severity of insufficiency, symptoms and left ventricular function [16]. Surgical intervention should be performed before pregnancy according to the criteria of valve diseases guidelines in case of symptomatic, severe failure of left ventricular dysfunction or left ventricular dilatation and repair should be considered first [3].

\subsubsection{Prosthetic Heart Valves}

Table 5. Anticoagulation strategies with mechanical prosthetic valve [17].

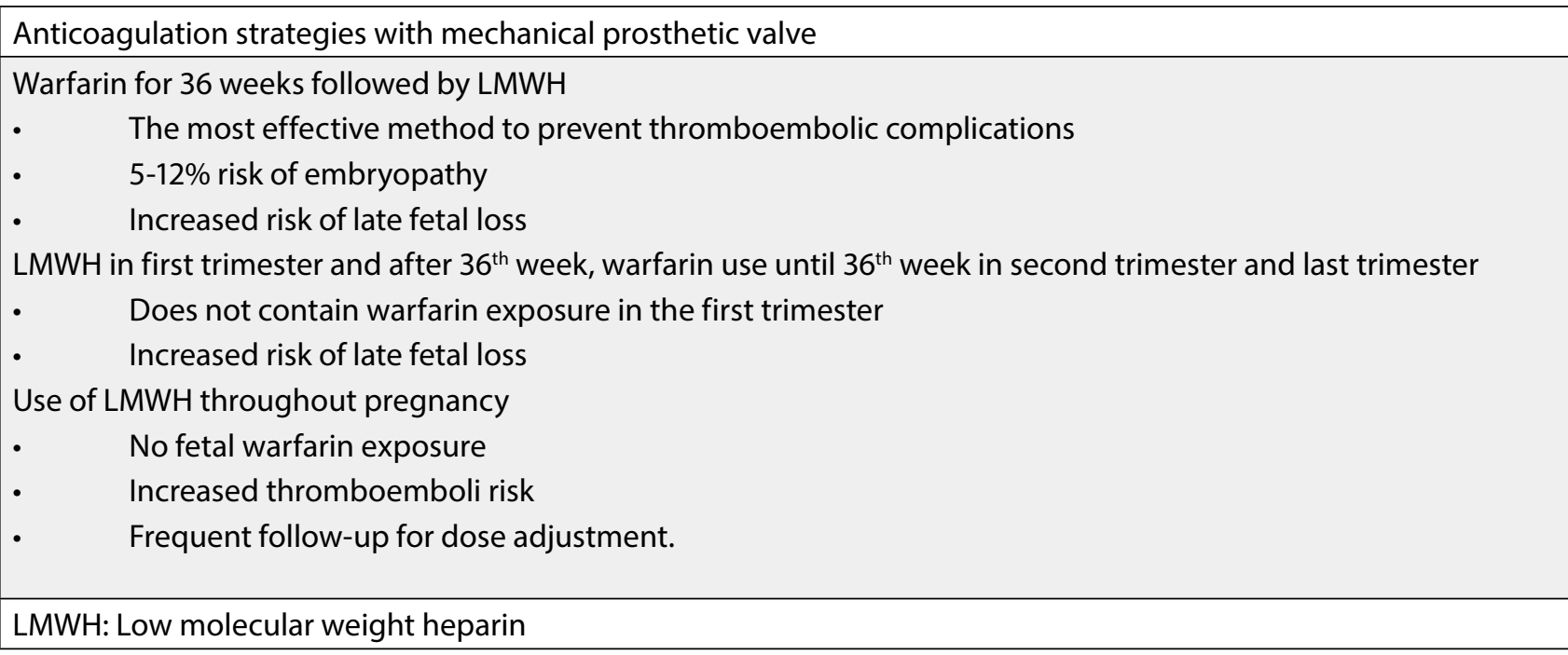

\subsection{Arrhythmia}

Patient with paroxysmal atrial arrhythmia should be considered to have catheter ablation prior to pregnancy because arrhythmia is more difficult to treat in pregnancy [15]. During pregnancy, acute episodes can be terminated by vagal maneuvers, intravenous adenosine or metoprolol. It is stated that when these treatment methods are ineffective and in the presence of preexcitation electrical cardioversion (DCCV) can be safely performed [3]. Ventricular arrhythmias require urgent treatment and urgent electrical cardioversion should be performed if it is 'persistent' or if it leads to hemodynamic deterioration. Most ventricular arrhythmias develop due to the underlying structural heart disease. Patients with normal heart structure are more likely to have fascicular or right ventricular outflow
The choice of prosthesis is very problematic in patients who are considering pregnancy and need valve implantation. Mechanical prostheses have excellent haemodynamic performance and long life. However, because of the need for anticoagulation, fetal and maternal complications increase. Bioprostheses provide good haemodynamic performance and the risk of thrombosis is much less. However, approximately $50 \%$ of bioprosthesis implanted women aged $<30$ years, there is deterioration in the valve structure within 10 years and this risk is higher in the mitral bioprosthesis [3]. All anticoagulant regimens increase maternal and fetal risk. Three different treatment strategies are recommended (Table 5). tract tachycardias. This type of ventricular tachycardia can respond well to verapamil and the chance of success with catheter ablation are higher in these patients [18].

\subsection{Ventricular Dysfunction}

The stress caused by the pregnancy can lead to symptomatic heart failure in previously asymptomatic patients, or decompensated heart failure may occur due to the development of peripartum cardiomyopathy. Mild shortness of breath and peripheral edema are common in pregnancy but patients with significant signs and symptoms should be evaluated for heart failure.

Although the treatment approach is the same as 
for non-pregnant patients, it is necessary to make changes in drug treatment. Cardioselective beta-blockers (metoprolol and bisoprolol) may be given by appropriate fetal monitoring. Hydralazine and oral nitrates can be used as vasodilators in place of angiotensin converting enzyme inhibitors (ACEls) and angiotensin receptor blockers (ARBs) [15]. Similarly, loop diuretics can replace aldosterone receptor antagonists [15].

\section{Peripartum Cardiomyopathy (PPCMP)}

PPCMP is seen in the last trimester or postpartum in the first five months [15]. Diagnosis is made by excluding other causes for heart failure. Multiparity, multiple pregnancy, family history, ethnicity, smoking, HT, DM, preeclampsia, malnutrition, advanced age or young age and long-term beta agonist use are predisposing factors [19]. The medical treatment management is similar to other causes of heart failure. If the deterioration of ventricular function continues, it is indicated that the risk of recurrence in the next pregnancy is $44 \%$ and that of the mortality risk is around $19 \%$ [20].

\section{Preoperative Evaluation in Pregnancy}

Approximately $0.2 \%-0.75 \%$ of pregnant patients need non-obstetric surgery [21]. Similar to the general population, the majority of surgical interventions required in pregnant patients are appendicitis and cholecystitis cases [22]. In cases where surgery is necessary, general approach is the same as those who are not pregnant. However, a multidisciplinary approach is needed in pregnant patients. Detailed history taking and physical examination are the basis of diagnosis. It should be taken into consideration that there may be changes in the location of the organs due to the growing uterus. Fetal and maternal risks must be taken into account when using diagnostic methods.

\subsection{Patient Selection / Preoperative Preparation}

Surgery should be performed independently of the trimester in emergent cases. If an elective intervention is needed and there is no effect on fetus, the surgical procedure should be delayed after birth. If surgery is needed and semi-elective, the optimal time period is indicated as second trimester [23]. At least 6 hours solid and at least 2 hours fluid intake restriction should be done before surgery [24]. 'The American College of Chest Physicians' recommends performing mechanical and / or pharmacological thromboprophylaxis in all surgical cases. LMWHs are safe treatment modalities recommended in this regard. Early mobilization and prophylaxis are recommended until the patient is mobilized after surgery [25]. The risk of preterm labor increases in the perioperative period. Prophylaxis with glucocorticoids is recommended if preterm delivery is expected or if it is highly probable and the fetus can survive [26].

\subsection{Anesthesia in Pregnancy}

Since fetuses may live, continuous intraoperative fetal monitoring is usually performed via transabdominal ultrasonography in the third trimester and late period of second trimester cases [26]. The type of anesthesia to be applied is determined according to the type and timing of surgery, maternal physiological changes and teratogenic effects. Regional anesthesia with peripheral nerve or neuroaxial block is considered safe in pregnancy. However systemic hypotension that may occur in this case and can lead to placental hypoperfusion and fetal risk can increase [27].

General anesthesia is usually performed because the surgical cases during pregnancy usually require laparoscopy or laporotomy. Preoxygenation has a vital importance in pregnancy because hypoxia can reduce placental blood flow. Propofol is generally used for induction. None of the inducing agents have been shown to be teratogenic [26].

\section{CONCLUSION}

Pregnant women with heart disease should be assessed by multidisciplinary approach by classifying them according to risk scorings. Patients should be followed up at well-equipped centers at regular intervals. Non-obstetric surgery should be performed independently of the trimester in emergent cases. If an elective intervention is needed, the surgical procedure should be delayed after birth. If surgery is needed and semi-elective, the optimal time period is second trimester

\section{CONFLICT Of INTEREST STATEMENT}

There is no conflict of interest related with our manuscript and was not supported by any grant or institution. 
[1] Weiss BM, von Segesser LK, Alon E, et al. Outcome of cardiovascular surgery and pregnancy: a systematic review of the period 1984-1996. Am J Obstet Gynecol 1998; 179: 1643-1653.

[2] Khairy $P$, lonescu-Ittu R, Mackie AS, et al. Changing mortality in congenital heart disease. J Am Coll Cardiol 2010; 56: 1149-1157.

[3] Regitz-Zagrosek V, Blomstrom Lundqvist C, Borghi C, et al. ESC Guidelines on the management of cardiovascular diseases during pregnancy: the Task Force on the Management of Cardiovascular Diseases during Pregnancy of the European Society of Cardiology (ESC). Eur Heart J 2011; 32: 3147-3197.

[4] Peters RM, Flack JM. Hypertensive disorders of pregnancy. J Obstet Gynecol Neonatal Nurs 2004; 33: 209-220.

[5] Stangl V, Schad J, Gossing G, et al. Maternal heart disease and pregnancy outcome: a single-centre experience. Eur J Heart Fail 2008; 10: 855-860.

[6] Siu SC, Sermer M, Colman JM, et al. Prospective multicenter study of pregnancy outcomes in women with heart disease. Circulation 2001; 104: 515-521.

[7] Thorne S, MacGregor A, Nelson-Piercy C. Risks of contraception and pregnancy in heart disease. Heart 2006; 92: 1520-1525.

[8] Drenthen W, Boersma E, Balci A, et al. Predictors of pregnancy complications in women with congenital heart disease. Eur Heart J 2010; 31: 2124-2132.

[9] Warnes CA, Williams RG, Bashore TM, et al. ACC/AHA 2008 guidelines for the management of adults with congenital heart disease: a report of the American College of Cardiology/ American Heart Association Task Force on Practice Guidelines (Writing Committee to Develop Guidelines on the Management of Adults With Congenital Heart Disease). Developed in Collaboration With the American Society of Echocardiography, Heart Rhythm Society, International Society for Adult Congenital Heart Disease, Society for Cardiovascular Angiography and Interventions, and Society of Thoracic Surgeons. J Am Coll Cardiol 2008; 52: e143-263.

[10] Drenthen W, Pieper PG, Ploeg M, et al. Risk of complications during pregnancy after Senning or Mustard (atrial) repair of complete transposition of the great arteries. Eur Heart J 2005: 26: 2588-2595.

[11] Genoni M, Jenni R, Hoerstrup SP, et al. Pregnancy after atrial repair for transposition of the great arteries. Heart 1999; 81 276-277.

[12] Yap SC, Drenthen W, Pieper PG, et al. Pregnancy outcome in women with repaired versus unrepaired isolated ventricular septal defect. BJOG 2010; 117: 683-689.

[13] Veldtman GR, Connolly HM, Grogan M, et al. Outcomes of pregnancy in women with tetralogy of Fallot. J Am Coll Cardiol 2004; 44: 174-180.

[14] Baumgartner $\mathrm{H}$, Bonhoeffer P, De Groot NM, et al. ESC
Guidelines for the management of grown-up congenital heart disease (new version 2010). Eur Heart J 2010; 31: 2915-2957.

[15] Emmanuel $Y$, Thorne SA. Heart disease in pregnancy. Best Pract Res Clin Obstet Gynaecol 2015; 29: 579-597.

[16] Lesniak-Sobelga A, Tracz W, KostKiewicz M, et al. Clinical and echocardiographic assessment of pregnant women with valvular heart diseases--maternal and fetal outcome. Int J Cardiol 2004; 94: 15-23.

[17] McLintock C. Thromboembolism in pregnancy: challenges and controversies in the prevention of pregnancy-associated venous thromboembolism and management of anticoagulation in women with mechanical prosthetic heart valves. Best Pract Res Clin Obstet Gynaecol 2014; 28: 519-536.

[18] Cleary-Goldman J, Salva CR, Infeld J, et al. Verapamilsensitive idiopathic left ventricular tachycardia in pregnancy. J Matern Fetal Neonatal Med 2003; 14: 132-135.

[19] Sliwa K, Hilfiker-Kleiner D, Petrie MC, et al. Current state of knowledge on aetiology, diagnosis, management, and therapy of peripartum cardiomyopathy: a position statement from the Heart Failure Association of the European Society of Cardiology Working Group on peripartum cardiomyopathy. Eur J Heart Fail 2010; 12: 767-778.

[20] Elkayam U, Tummala PP, Rao K, et al. Maternal and fetal outcomes of subsequent pregnancies in women with peripartum cardiomyopathy. N Engl J Med 2001; 344: 1567-1571.

[21] Soper NJ. SAGES' guidelines for diagnosis, treatment, and use of laparoscopy for surgical problems during pregnancy. Surg Endosc 2011; 25: 3477-3478.

[22] Fatum M, Rojansky N. Laparoscopic surgery during pregnancy. Obstet Gynecol Surv 2001; 56: 50-59.

[23] Practice ACoO. ACOG Committee Opinion No. 474: nonobstetric surgery during pregnancy. Obstet Gynecol 2011; 117: 420-421.

[24] American Society of Anesthesiologists Task Force on Obstetric A. Practice guidelines for obstetric anesthesia: an updated report by the American Society of Anesthesiologists Task Force on Obstetric Anesthesia. Anesthesiology 2007; 106: 843-863.

[25] [Guyatt GH, Akl EA, Crowther M, et al. Executive summary: Antithrombotic Therapy and Prevention of Thrombosis, 9th ed: American College of Chest Physicians Evidence-Based Clinical Practice Guidelines. Chest 2012; 141: 7S-47S.

[26] [Stewart MK, Terhune KP. Management of pregnant patients undergoing general surgical procedures. Surg Clin North Am 2015; 95: 429-442.

[27] Reitman E, Flood P. Anaesthetic considerations for non-obstetric surgery during pregnancy. Br J Anaesth 2011; 107 Suppl 1: i72-78. 